\title{
A Comparative Study of Needlescopic Grasper Assisted Single Incision versus Three Port versus Pure Single Incision Laparoscopic Cholecystectomy
}

\author{
Bum-Soo Kim, M.D., Ph.D. \\ Division of Hepatobiliary Surgery and Liver Transplantation, Department of Surgery, Kyung Hee University Hopital, Kyung Hee University School of \\ Medicine, Seoul, Korea
}

\begin{abstract}
This study compared the surgical outcomes of single-incision with needlescopic grasper (nSILC) versus three-port (TPLC) versus pure single-incision laparoscopic cholecystectomies (pSILC). The present study showed similar surgical outcomes between the pSILC and nSILC procedures. However, the operative time for the nSILC group was longer than that for the TPLC group but shorter than that for the pSILC group. Therefore, nSILC is a feasible surgical procedure for patients with benign gallbladder disease compared to TPLC and an effective approach to overcome the limitations of pSILC.
\end{abstract}

Keywords: Laparoscopic cholecystectomy, Gallbladder, Needlescopic

\author{
Received October 30, 2019 \\ Revised November 13, 2019 \\ Accepted November 14, 2019 \\ Corresponding author \\ Bum-Soo Kim \\ Division of Hepatobiliary Surgery \\ and Liver Transplantation, \\ Department of Surgery, Kyung Hee \\ University Hopital, Kyung Hee \\ University School of Medicine, 23 \\ Kyunghee-daero, Dongdaemun-gu, \\ Seoul 02447, Korea \\ Tel: +82-2-958-8241 \\ Fax: +82-2-966-9366 \\ E-mail: kbs420@hanmail.net \\ ORCID: \\ https://orcid.org/0000-0003-2216-0403
}

Copyright $\odot 2019$ The Journal of Minimally Invasive Surgery. All rights reserved.

This is an Open Access article distributed under the terms of the Creative Commons Attribution Non-Commercial License (http:// creativecommons.org/licenses/by-nc/4.0/) which permits unrestricted non-commercial use, distribution, and reproduction in any medium, provided the original work is properly cited.

\section{INTRODUCTION}

Laparoscopic cholecystectomy has been the gold standard for the surgical treatment of gallbladder disease since $1985^{1,2}$ This procedure results in less postoperative pain, shorter hospital stays, better cosmesis, and less disability for work compared to conventional open cholecystectomy. ${ }^{2,3}$ With the development of laparoscopic instruments and techniques, many surgeons have tried to reduce the number and size of the ports. ${ }^{4}$

Navarra et al. ${ }^{5}$ reported the world's first single-incision laparoscopic cholecystectomy (SILC).

The removal of the gallbladder through a single periumbilical incision using SILC technology reduced scarring, improved cosmetic results, reduced postoperative pain, and improved the quality of life. ${ }^{6}$

Despite these advantages, many surgeons are not satisfied with SILCs because of its ergonomic problems and the resulting reduction in surgeon comfort. ${ }^{6}$ These problems cause insufficient gallbladder traction during the dissection of Calot's triangle, making it difficult to obtain a "critical view of safety" (CVS). 
To overcome this problem, single-incision robotic cholecystectomy (SIRC) was introduced. The operative time of an SIRC is similar to that of an SILC. SIRC is as safe and effective as SILC. However, the total cost of SIRC is significantly higher than that of an SILC?

In this study, the authors compared the surgical outcomes of patients who underwent SILCs with needlescopic graspers (nSILC) to those with pure SILC (pSILC) and conventional three-port laparoscopic cholecystectomies (TPLC).

The analysis showed that the surgical outcomes were similar between the pSILC and nSILC patients. However, consistent with another study, ${ }^{8}$ the operative time for nSILCs was longer than that for TPLCs, but shorter than that for pSILCs.

The authors suggest that problems performing SILCs can be successfully overcome with nSILCs. Furthermore, this approach allows for a CVS provided by the needlescopic grasper for lateral traction and the snake liver retractor for cephalad space traction of the gallbladder during SILCs.

Therefore, nSILC is a surgical procedure suitable for patients with benign gallbladder disease compared to TPLC and an effective approach to overcome the limitations of pSILC.

As the authors mentioned, this study was a retrospective review with selection bias and small sample size. However, the findings may be helpful for surgeons working at small and medium-sized hospitals that do not have robotic systems to perform SILCs and provide a foundation for prospective studies in the future.

\section{ORCID}

Bum-Soo Kim, https://orcid.org/0000-0003-2216-0403

\section{CONFLICT OF INTEREST}

None.

\section{FUNDING}

None.

\section{ACKNOWLEDGMENTS}

None.

\section{REFERENCES}

1) Begos DG, Modlin IM. Laparoscopic cholecystectomy: from gimmick to gold standard. J Clin Gastroenterol 1994;19:325-330.

2) Soper NJ, Stockmann PT, Dunnegan DL, Ashley SW. Laparoscopic cholecystectomy. The new 'gold standard'? Arch Surg 1992; 127:917-923

3) Schirmer BD, Edge SB, Dix J, Hyser MJ, Hanks JB, Jones RS, Laparoscopic cholecystectomy. Treatment of choice for symptomatic cholelithiasis. Ann Surg 1991;213:665-677.

4) Pan MX, Jiang ZS, Cheng Y, et al. Single-incision vs three-port laparoscopic cholecystectomy: prospective randomized study. World J Gastroenterol 2013;19:394-398.

5) Navarra G, Pozza E, Occhionorelli S, Carcoforo P, Donini I. Onewound laparoscopic cholecystectomy. Br J Surg 1997;84:695-695.

6) Lurje G, Raptis DA, Steinemann DC, et al. Cosmesis and Body Image in Patients Undergoing Single-port Versus Conventional Laparoscopic Cholecystectomy: A Multicenter Double-blinded Randomized Controlled Trial (SPOCC-trial). Ann Surg 2015;262: 728-735.

7) Migliore M, Arezzo A, Arolfo S, Passera R, Morino M. Safety of single-incision robotic cholecystectomy for benign gallbladder disease: a systematic review. Surg Endosc 2018;32:4716-4727.

8) Kim MJ, Kim TS, Kim KH, An CH, Kim JS. Safety and feasibility of needlescopic grasper-assisted single-incision laparoscopic cholecystectomy in patients with acute cholecystitis: comparison with three-port laparoscopic cholecystectomy. J Laparoendosc Adv Surg Tech A 2014;24:523-527. 